\title{
Г.М. Ибатуллина
}

Стерлитамакская государственная педагогическая академия

\section{Две инициации: о символическом смысле одного эпизода в сюжете романа Б. Пастернака «Доктор Живаго»}

Аннотащия: Мифопоэтический анализ восьмой главы первой части романа «Доктор Живаго» позволяет объяснить параллелизм жизненных ситуаций, имеющих переломно-знаковый характер в судьбах Ники Дудорова и Юры Живаго. Сюжет архаической (языческой) инициации, определяющей пути формирования личности Дудорова, оказывается в художественно-смысловом контрапункте с христоцентрической логикой судьбы главного героя произведения.

A mythical and poetical analysis of "Doctor Zhivago", Part I, Chapter 8, makes it possible to explain the parallelism of the key events in the lives of Nikki Dudorov and Yury Zhivago. The story of the ancient pagan initiation that plays a pivotal role in the formation of Dudorov's personality stands in an artistic and logical counterpoint to the progression of Zhivago's life based on Christ-centered traditions.

Ключевые слова: сюжет, инициация, мифопоэтический контекст.

Plot, initiation, mythical and poetics context.

УДК: 821.161.1.09.

Контактная информация: Башкортостан, г. Стерлитамак, пр. Ленина, 49. СГПА, кафедра русской литературы. Тел. (3473) 262010. E-mail: GuzelAnna@yandex.ru.

И поэтика романа «Доктор Живаго», и его художественно-философская парадигматика были и остаются в поле зрения исследователей на протяжении многих лет. Можно назвать целый ряд работ, обозначивших ключевые моменты научного дискурса, генерируемого одним из эпохально-знаковых текстов XX века: это работы В.С. Баевского, Б. Гаспарова, Н.Л. Лейдермана, Ю.Б. Орлицкого, И.П. Смирнова, Е. Фарыно, Н.А. Фатеевой, Л. Флейшмана и др. Вместе с тем общая картина образно-смысловой архитектоники романа, с его сложной многоуровневой организацией, вряд ли еще близка к завершению. На наш взгляд, исследование отдельных художественных локусов произведения способно не только дополнить общую картину, но и высветить более отчетливо внутренние связи между составляющими ее смыслопорождающими структурами.

Седьмая и восьмая главы первой части романа особенно репрезентативны в этом отношении: они являют удивительный пример художественно-смыслового контрапункта, актуализированного на уровне символического подтекста и во многом определяющего пути понимания основных сюжетных коллизий произведения. «Две инициации» - так можно условно обозначить суть этого контрапункта, возникающего в результате сюжетно-композиционно-смыслового взаимоотражения двух эпизодов романа. В этой работе речь пойдет о 8 главе первой части «Доктора Живаго»: микроанализ этого фрагмента с очевидностью проявляет ситуацию рефлексийно-диалогических взаимоотражений микросюжета главы,

(C) Г.М. Ибатуллина, 2012 
сюжета романа в целом и его метасюжетной парадигмы, порождаемой системой связей и отношений между смысловыми уровнями текста, подтекста и контекста.

Перед нами история одного дня из жизни Ники Дудорова - персонажа, который наряду с Мишей Гордоном зримо или незримо сопутствует Юрию Живаго на протяжении всего романа. Судьбы этих персонажей - не просто фон, на котором рельефно высвечивается личность и судьба главного героя; они создают тот единый контекст - социально-исторический, психологический, общекультурный, повседневно-жизненный - благодаря которому только и может быть осознана уникальность и исключительность Живаго. Мистерия жизни главного героя разворачивается в совершенно иных бытийных планах и контекстах, нежели судьбы наиболее близких к нему людей. Различие между героями обозначено уже с первых страниц романа, на которых мы встречаемся с тремя «русскими мальчиками».

И Гордон, и Дудоров - люди, чьи жизненные идеалы, духовные ценности не только определяются, но и опреде́ливаются контекстами эпохи, идеологическими установками социума, «человеческими, слишком человеческими» ценностями, даже если эти ценности высокого порядка, даже если их идеи полемичны по отношению к общепринятым мировоззренческим догматам. Они не чувствуют себя в «плену у времени», в диалоге с которыми они стремятся жить, в то время как Живаго не умеет жить иначе, чем в диалоге с вечностью. И здесь не просто разница личностных масштабов и талантов, здесь более глубокая духовноличностная разнокачественность, разносубстанциальность.

Живаго и Дудоров - это люди, бытие которых имеет разную онтологию, они живут в разных мирах и, соответственно, разных мифах; их вселенные имеют разные ценностные системы координат и смысловые точки отсчета, несмотря на общность пространственно-временных параметров. Мир Живаго - мир христианского мифа ${ }^{1}$, он изначально богоцентричен и христологичен; мир Дудорова и Гордона - антропоцентричен и антропологичен. Согласно логике последнего, основная цель становления человека - утвердить себя в этом мире, обрести и конституировать свой личностный, социальный, психологический статус в нем «выйти в люди»; в самых общих чертах его можно охарактеризовать как мир, организованный по модели языческого мифа.

В рамках архаико-мифологической, языческой модели миропонимания и ее аксиологических координат совершается первая инициация Ники Дудорова, представленная в 8 главе романа.

Пространство происходящих здесь событий благодаря особой логике изображения как бы удваивается: во-первых, это пространство жизни повседневноузнаваемой, наполненной привычными реалиями социальных и психологических связей и отношений. Во-вторых, логика повествования порождает представление об особой, сверхэмпирической реальности, в которой каждое из изображенных событий, фактов, деталей обнажает свой сущностный, архетипический смысл, узнаваемый и объясняемый в контекстах мифологического миропонимания. Миф здесь у Пастернака не является метафорой реальности (или только лишь контекстом интерпретации происходящего), он существует в «недрах» самой обыденноповседневной реальности как некий параллельный мир и может быть «высвечен» в ней так же, как рентгеновские лучи высвечивают незримые структуры материальных тел. Это удвоение реальностей, параллелизм миров обоснованы в системе изображения Пастернака особыми мотивировками. Все происходящее в этой гла-

\footnotetext{
${ }^{1}$ Говоря о мифе, мы имеем в виду то его понимание, которое наиболее полно и точно было эксплицировано А.Ф. Лосевым: миф есть не просто модель реальности, пусть даже универсальная и максимально ей адекватная; миф есть сама живая реальность в ее глубинных онтологически укорененных первообразах; «все на свете есть миф» [Лосев, 1994 c. 915].
} 
ве мы воспринимаем не только через авторский взгляд, но и сквозь призму детского мирочувствия, отражающую реальность иначе, чем взрослые; в результате создается эффект остраненного видения. Призма детского сознания порождает своеобразную промежуточную реальность, пограничную и переходную между миром обыденным и миром мифа. Детское сознание само по себе в значительной мере мифологично, и потому переходы от погруженного в быт существования к бытию в мифе для него естественны и органичны.

Мифопоэтические и символические смыслы изображаемых картин и ситуаций актуализированы в повествовании рядом нарративно-образных, стилистических сигналов, и целым рядом образов и деталей, выполняющих знаковую функцию, функцию прямых и косвенных отсылок к мифологическим контекстам, и существующих в ситуации многовекторных рефлексийно-смысловых взаимоотражений.

Пространственной метафорой перехода в ино-реальный, параллельный мир и знаком переключения контекстов становится уже самое первое микрособытие анализируемой главы. Убегая от разыскивающих его гостей, Ника прячется под кровать, а затем через окно уходит в парк. Интересно, что здесь мы встречаемся с эффектом двойной метафоры, с удвоением метафорического смысла конкретного действия. Спрятаться под кровать и, выскочив через окно, убежать в парк в данной ситуации для Ники - единственная возможность бегства от нежелательных гостей, но в мире детского сознания и поведения эти действия обладают еще и собственным метафорическим смыслом. Залезть под кровать или выскочить в окно для ребенка может быть и жестом независимости, реализацией внутренней потребности в свободном, нерегламентированном действии; одновременно это может быть творческим актом, выражающим внутреннюю потребность в миромоделировании, миропорождении. Ведь спрятаться под кровать - значит создать свой собственный, «иной» мир; вылезти в окно - значит ощутить себя в иной пространственно-временной реальности, отличной от той, где выходят только через дверь. Повествовательный контекст в данном случае ситуативно обыгрывает этот детский поведенческий жест, используя уже наделенное метафорическим смыслом действие для создания художественной метафоры - метафоры перехода в «ино-реальность». На уровне подтекста художественный язык Пастернака реализует существенные для мифологического мышления семантические коды, актуализируя оппозиции «дом - лес (парк)», «свой - чужой». Вспомним, чтобы пройти инициацию, необходимо покинуть обжитую территорию и погрузиться в пространство чуждых человеку стихий.

Не только пространство, но и время изображаемых событий представлено как время особое, отличное от привычных ритмов повседневности. Сам описанный день оказывается для героя знаковым; он отмечает грань, точку перехода из мира детства в мир «большой». Мы узнаем, что бегство от гостей вызвано не только неприязнью к ним и нежеланием их видеть, но особым душевным состоянием Ники в этот день: «Он был сегодня сам не свой и предшествующую ночь не спал. Ему шел четырнадцатый год. Ему надоело быть маленьким. Всю ночь он не спал и на рассвете вышел из флигеля» [Пастернак, 1990, с. 21].

Ряд деталей нарративного строя рассказа о Нике также косвенно акцентирует значимость этого дня. Такова, к примеру, стилистически маломотивированная тавтология в процитированом сообщении о том, что предшествующую ночь мальчик не спал.

Таким образом, прыжок Ники в окно оказывается знаковым: знаком ухода бегства - изоляции от реальности повседневной в реальность иную, мифологизированную. Подросток ушел в парк, а парк уже утром того же дня открылся ему как иномирье. Одним из концептуально значимых, неоднократно повторяющихся образов, акцентирующих мифологичность этой реальности, становится архетипический в своей основе образ змеи. Встреча со змейкой - первая утренняя встреча 
героя с живым существом этого мира. Этот момент нельзя посчитать случайной или фоновой деталью пейзажного описания, хотя бы потому, что традиционная и наиболее характерная, замечаемая человеком деталь в картине пробуждающейся природы, как правило, утреннее многоголосие птичьего пения; между тем, перед нами картина мира практически беззвучного, живущего лишь молчаливым, бессловесным общением с человеком. «Вдруг серебристая струйка ртути, такая же, как капли росы в траве, потекла в нескольких шагах от него. Струйка текла, а земля ее не впитывала. Неожиданно резким движением струйка метнулась в сторону и скрылась. Это была змея медянка. Ника вздрогнул» [Пастернак, 1990, с. 21]. Необычность, остраненность видения в данном отрывке (особенно во второй, выделенной нами, фразе) подчеркивает и особую семантику образа. Инородность, иноприродность этого существа оттенена еще и тем, что небольшой изобразительный фрагмент насыщен «неорганическими», «металлическими» мотивами: серебро, ртуть, медь встречаются здесь в границах четырех коротких предложений. Сама змейка оказывается причудливым симбиозом органической и неорганической природы и соответственно, живого и неживого, одушевленного и неодушевленного, естественного и искусственного начал. Подобное же единство, слияние или взаимопереход первичных природных стихий и онтологическижизненных начал: огня, воздуха, воды, земли, дерева, металла, растений, животных, света и тьмы, женского и мужского, детского и взрослого, душевного и телесного, рационального и иррационального, человеческого и вне-человеческого (причем, последнее представлено в разных своих ипостасях: как божественное, демоническое или животно-биологическое), - а также и других, ассоциативно с ними связанных бытийных сил и энергий, обнаружим во многих элементах пейзажных описаний и событийных ситуаций восьмой главы. В символическом подтексте повествования все эти детали являются очевидной отсылкой к образам хтоническим - к представлениям о том первозданном состоянии бытия, которое архаические мифы называли Хаосом и считали его материнским лоном всего сущего (см., например, об этом: [Топоров, 1992, с. 579-582]); изначальные субстанции мироздания не утратили еще здесь ни своего единства, ни способности к трансмутациям и преображению. Именно через погружение в эту первичную бытийную реальность и возможно для человека подлинное глубинное преображение. Рассмотрим подробнее некоторые образы анализируемой главы, отражающие вышеперечисленные субстанциальные связи и отношения.

Хтонически-змеиными ассоциациями насыщено изображение тени деревьев, покрывающей землю в парке: тень была «длинная, мокрая, петлистая». Змееподобными выглядят в изображении Пастернака и длинные, перепутанные, цепляющиеся за руки и ноги стебли водяных лилий, в заросли которых попадают Ника и Надя. И, наконец, в завершающем эпизоде главы, по-змеиному мокрый след оставляют за собой герои рассказа, выбравшиеся из пруда, едва не утонув в нем. Сам их путь лежит «по пыльному подъему, кишевшему змеями, невдалеке от того места, где утром Ника увидал медянку» [Пастернак, 1990, с. 23].

Мир, в который попадает герой, с привычной точки зрения действительно наполнен странностями. Природные стихии обретают здесь иные качества, невозможные в обычной реальности. «Струйка», т.е. влага, здесь не впитывается землей; живые существа одновременно похожи и на растения, и на животных: вспоминая о «неуклюжем тропическом великане» с листьями, «похожими на слоновые уши», «Ника не мог привыкнуть к мысли, что это дерево - растение, а не животное» [Там же, с. 22].

Здесь нет ничего неодушевленного. Более того, здесь теряется или приобретает какое-то иное качество само различие между живым и неживым: листья осины кажутся нарезанными из жести и вместе с тем они всецело охвачены живым трепетом. Животное существо - змейка - соединяет в себе качества практически 
всех природно-мифологических стихий: ее облик создается взаимоотражением образов света, воды, земли, металлов, растений.

Даже образ тени в парке с «продолговатыми просветами, похожими на пальцы девочки» насыщается ассоциативными семантическими обертонами, вызывающими в читательском сознании представление о живом существе.

Преобладающей стихией этого мира, так же, как и практически во всех мифологиях, оказывается стихия воды. Акватические образы являются лейтмотивом пейзажных описаний и достигают развернутой кульминации в сцене катания на лодке. Традиционно во многих мифологических культурах водные стихии связываются с женской ипостасью мировых демиургических сил. Мир, изображенный Пастернаком, созидается энергиями мужского и женского начал, но второму из них здесь явно отводится ведущая роль. Мотив пронизывающей мир и хранящей в себе некую тайну стихии женственности прочитывается уже в первом пейзаже главы. Имеются в виду не только аллюзии, порождаемые уподоблением просветов в тени пальцам девочки, но и вся картина утреннего парка, окутанного влагой и тенью, как покрывалом, «источающим одуряющее благоухание утра». Тень на земле действительно напоминает большое узорчатое покрывало, и сравнение ее с влажным войлоком в этом контексте воспринимается совсем не случайным. Все это атрибуты женского начала, несущего в себе энергии объединения, воплощения-материализации и преображения.

Не только мир, куда попадает герой, живет логикой мифа, но и события, с ним происходящие в этом мире, отражают в себе один из древнейших мифологических сюжетов - сюжет инициации. Замечательно, что не только общий смысл этого сюжета реконструирован в повествовании Пастернака, но и основные элементы его структуры, первый из которых - обособление, изгнание, уход, бегство - уже был обозначен нами выше. (Об архетипическом значении сюжета инициации и его событийно-смысловых фазах см. в работах В.Я. Проппа [Пропп, 1986], В.И. Тюпы [Тюпа, 1996]).

Следующая стадия - искушение - также отчетливо выделяется в структуре главы: она представлена эпизодом заклинания дерева. Эта сцена, где в «безумном превышении своих сил» Ника пытается повелевать миром, содержит прямые отчетливые отсылки к мифологическим контекстам. Уже первая фраза героя в этом фрагменте - «Как хорошо на свете!» - несет в себе отголосок того экстатического наслаждения миром, которое было доступно человеку лишь на заре творения и получило отражение в мифологических представлениях о Рае или Золотом веке. Мир в это утро действительно воспринимается Никой как новорожденный, только что открывшийся его сознанию и «одуряющий» своим благоуханием; контекстуально значимо и то, что каждое утро есть метафора первотворения в мифе. В общем символизированном контексте повествования обнаруживается и смысловая значимость композиционного сближения двух эпизодов: сцена с деревом следует сразу за встречей Ники со змейкой, что особым образом интонирует мотив искушения.

Эпизод с деревом окружен целым ореолом ассоциативно-символических аллюзий, актуализирующих в читательском сознании различные мифопоэтические мотивы. «Будете как боги, - искушал змей первый людей, - если вкусите плодов с этого дерева». «Если Бог есть, то он это я», - думает Ника [Пастернак, 1990, c. 21]. Подросток переживает основное и самое опасное для человеческой души искушение - искушение своеволия и самообожествления. Мысль об опасности, таящейся в подобной иллюзии, оттеняется и образом дерева, участвующем в метафорическом искушении мальчика. Ни одно дерево, кроме осины, не могло бы подыграть его искусителю, и не только потому, что в мифопоэтических поверьях осина связана с недобрыми для человека силами. В игру включаются и конкретноприродные реалии, так как лишь осина обладает удивительной естественной способностью от всецелого и непрерывного трепетания своей кроны перейти на ка- 
кое-то время в состояние полной неподвижности. Осина в этой ситуации не становится, конечно, символом, метафорой или хотя бы аллюзией того Древа, плодами которого искушены были Адам и Ева; но образ ее в данном контексте как бы рифмуется с образом Того Самого Древа, превращаясь в трансформированное большой контекстуальной дистанцией его отражение, в его смысловую рифму. Художественный язык прозаического повествования Пастернака в данном случае следует логике поэтической речи. Не случайно, «единство языковой творческой личности» и «изучение литературного «билингвизма» [Фатеева, 2003, с. 81] Пастернака как поэта и прозаика вызывают столь пристальный интерес исследователей.

Изображенный здесь эпизод на первый взгляд наиболее близок к мифу будь то библейское предание или языческий ритуал магического заклинания дерева. Но с другой стороны, он и наиболее дистанцирован от мифа открытым смысловым раздвоением ситуации: в контексте «реального» пространствавремени перед нами может быть случайное и естественное совпадение душевного порыва мальчика и действия природных сил; в контексте «ино-реального», мифического бытия - перед нами образ язычески понимаемого утверждения власти человека над природой посредством магии, что в рамках христианской системы ценностей воспринимается как искушение. Сама возможность смыслового раздвоения ситуации - «совпадение» или «победа» уже есть знак искушения: искушения поверить в то, во что хочется поверить и обмануться иллюзией своего всемогущества.

Благодаря подобным ситуациям смыслового удвоения (а в данном фрагменте и утроения: реальность - языческий миф - христианский миф), образносмыслового обыгрывания и взаимоотражения контекстов повествование Пастернака не превращается в миф, так как при этом разрушается целостность и замкнутость мифологического сознания. Двуплановость нарративной структуры порождает образ, отражение мифа, возникающий как результат действия принципов художественной рефлексии, т.е. такого взаимоотражения художественных структур текста, когда каждый из них становится объектом образного «осознания», рефлексии для другого, оказываясь, в результате, не только средством и формой изображения, но объектом и предметом изображения: рождается художественно осознанный образ другого художественного образа, к примеру, живущего по законам мифа. Так возникает и в тексте Пастернака не просто мифологизированный образ, но образ мифа как особой модели реальности, вступающей в диалогические отношения с иными ее оформляющими моделями ${ }^{1}$.

В логике повествовательного строя главы значимым становится и то, что описанное событие рождает в душе мальчика не только ницшеанскую радость всемогущества, но именно после него мы узнаем о тех наплывах агрессии, которые переживает Ника в этот день. Попытка не в себе ощутить Бога («я - это Он»), а Бога подменить собой («он - это я») ${ }^{2}$ пробуждает в человеке энергии разрушительные. Ника возмущается «всем на свете», негодует на Воскобойникова, на гостей, на мать, особенно на Надю, которой уже 15 лет, и Нике кажется, что она задирает нос и говорит с ним, «как с маленьким». «Я ее ненавижу», - повторяет он про себя. «Я ее убью! Я позову ее кататься на лодке и утоплю» [Пастернак, 1990, c. 22]. Эта по-детски преувеличенная угроза едва не становится реальностью, когда Ника и Надя, катаясь на лодке, падают в пруд.

\footnotetext{
${ }^{1}$ Подробнее о художественной рефлексии см.: [Ибатуллина, 2006а; 2008, с. 273-287].

2 Поскольку человек создан «по образу и подобию Божию» и наделен божественным духом, он вправе сказать «Я есмь Бог», т.е. «во мне есть Бог», но инверсия фразы («Бог это я» - так звучат слова Ники) уведет ее от истины; личность может быть обожена, восстановив в себе образ Бога, но сущность Бога, разумеется, не может быть исчерпана ни одной из сотворенных им личностей.
} 
Данная фаза археосюжета (термин В.И. Тюпы) - испытание смертью - считается минимальной, но кульминационной в его структуре; в повествовании Пастернака ей также отведено центральное место, не случайно, этот фрагмент занимает по объему половину всей восьмой главы. Эпизод включает в себя и завершающий элемент сюжета инициации - преображение и возвращение в «мир людей».

Семантика возрастной и социальной инициации тесно переплетена здесь с мотивами половой инициации, имеющими ярко выраженный эротический оттенок. Мальчик и девочка не просто становятся взрослыми, они ощущают себя мужчиной и женщиной, в которых дифференцируются и по-разному инкарнируются мужские и женские мировые стихии и энергии.

Сюжет возрастной инициации подростка, достигшего половой зрелости и ищущего обрести статус взрослого полноценного члена социума воплощен в изображении Пастернака с поразительной художественной конкретностью мифопоэтической символики. Мотивы женских и мужских космических энергий, пронизывающих и созидающих мир, прослеживаются на протяжении всего повествования. В анализируемой сцене они достигают своей кульминации, воплощаясь в образах с отчетливо выраженной женско-мужской телесно-сексуальной символикой. «Край пруда порос сплошь кувшинками. Лодка взрезала эту гущу с сухим шорохом. В разрывах заросли проступала вода пруда, как сок арбуза в треугольнике разреза. Мальчик и девочка стали рвать кувшинки. Оба ухватились за один и тот же нервущийся и тугой, как резина, стебель. Он стянул их вместе. Дети стукнулись головами... Стебли перепутывались и укорачивались, белые цветы с яркою, как желток с кровью, сердцевиной уходили под воду и выныривали со льющейся из них водою» [Пастернак, 1990, с. 22]. Здесь перед нами не только ряд изобразительных деталей, окруженных семантической аурой, позволяющей ассоциировать их с образами женско-мужской телесности («вода, как сок арбуза в треугольнике разреза», «нервущийся и тугой, как резина, стебель»), но и мифопоэтически обозначенные мотивы дефлорации и утраты девственностидетскости. Белая водяная лилия помимо того, что традиционно является символом чистоты и невинности, имеет также мифологическое значение цветка, возникшего из первоначального мирового океана и служащего колыбелью солнцу. Лилия связана с миром хтоническим и одновременно с мотивами рождения и оплодотворения. Сорвать лилию - значит лишить девушку невинности (см.: [Лосев, 1994, c. 55]).

Особо яркое впечатление в процитированном фрагменте производит цветовая гамма изображения, явно символичная в контекстах мифопоэтических ассоциаций. Образ «белых цветов с яркою, как желток с кровью, сердцевиной» еще более усиливает сексуально-эротическую семантику сцены, внося также смысловые обертоны, связанные с мотивами оплодотворения - зачатия - рождения. Повествование Пастернака здесь буквально насыщено художественными деталями, оттеняющими эту семантику. Лодка, из которой Ника и Надя рвут цветы, все более накреняя ее «и почти лежа рядом на опустившемся борту», оказывается образом многозначным. Это и мифологическая ладья, в которой возможен спуск в нижний, хтонический мир, стихией которого является стихия воды; лодка - это и подобие колыбели, в которой обретают себя новорожденные и преображенные человеческие существа после пережитой инициации, причастившей их царству смерти. И если вода в мифах - стихия рождающего материнского лона, то лодка здесь уподобляется и вратам этого лона, из которого является на свет новорожденный.

Объемлющая все происходящее водная стихия представлена амбивалентно: как увлекающая в царство смерти и как очищающая, перерождающая, оплодотворяющая. Белые лилии с «яркою, как желток с кровью, сердцевиной» погружаются в воду и выныривают «со льющеюся из них водою». Сакрально-символическое 
очищение крови мировыми водами ассоциативно проецируется затем и на героев, у которых точно так же после того, как они выбрались из пруда, «вода ручьями текла из их башмаков и карманов» [Пастернак, 1990, с. 23]. (Заметим, что здесь мы вновь встречаемся с моментом смысловой рифмы, о котором уже говорилось выше).

Диалектика единства и борьбы противоположностей в женских и мужских началах мироздания отражена и в диалоге, который ведут Ника и Надя в лодке, и в той драке, которую затеял Ника и которая в данном контексте также приобретает оттенок эротический: герои ведут разговор и начинают ссориться «почти лежа рядом на опустившемся борту»; поводом же к ссоре становится вопрос Ники, за кого собирается выйти замуж Надя, «когда вырастет». Пригрозив утопить ее за «дерзости» в ответе, «он схватил ее поперек туловища. Между ними завязалась драка» [Там же].

Погружение в нижний мир, в перерождающее царство первичного хаоса завершается преображением героев, хотя и сопровождается мучительными и доставляющими страдание ощущениями: «... они молчали и еле дышали, подавленные бессмыслицей случившегося. ....у Ники болело все тело, словно ему перебили палкою ноги и руки и продавили ребра» [Там же]. Болезненны объятия смерти, так же, как порой и объятия любви, но такова цена рождения нового «я»: «Наконец тихо, как взрослая, Надя проронила: “Сумасшедший!”, - и он также повзрослому сказал: “Прости меня”» [Там же]. Ника теперь уже не мечтает о всемогуществе и самоутверждении, меняется его представление о жизненных ценностях, теперь его мечты вполне очеловечены, просты, но мудры.

Следующий затем подъем по пыльной дороге, кишащей змеями, вновь, как и бегство героя в парк в начале главы, превращается в пространственную метафору перехода из «иномирья» в реальность земной человеческой жизни.

Итак, в исследуемой главе романа воссоздается образ архаической ритуальной инициации, реконструирующий основные черты и элементы ее структуры. Мы уже отмечали, что логика, по которой развивается личность и судьба Ники Дудорова - логика языческого, дохристианского мифа. В эту смысловую парадигму художественной мыслью Пастернака вписаны и контексты ветхозаветного сознания, и, что особенно интересно, те контексты, которые порождаются романтическим мироощущением байронического типа. Черты романтического субъективизма и романтически понимаемой революционности совершенно очевидны в мечтаниях Ники-подростка. По мысли Пастернака, и языческое, и ветхозаветное сознание, романтический субъективизм и революционная идеология нового времени обладают некоей общностью. Все они предполагают принципиальную и изначальную конфликтность отношений человека и мира. В рамках этой логики человек утверждает свою личность в противоборстве с миром, поскольку цели человеческого «я» и мировое целое изначально кажутся рассогласованными. Отметим еще раз, что это справедливо и для ветхозаветного сознания, так как человеческая личность здесь понимается испорченной грехопадением и отторгнутой от Бога. Такова логика бытия человечества дохристианской эры, которая еще не знала Спасителя, Искупителя, открывшего пути примирения с миром и его Творцом. Художественная мысль Пастернака приводит к выводу, что человечество, живущее законами подобного миропонимания, все еще не переросло подростковой стадии своего развития, поскольку его основной жизненной ценностью и целью остается самоутверждение.

Логика судьбы и личности Юрия Живаго, как говорилось выше, качественно иная и обладает внутренней смысловой христоцентричностью. Мистерия его жизни - это не обрядово-ритуальная мистерия, направленная на самоутверждение личности и конституирование ее определенного духовно-бытийного статуса. Это мистерия самопожертвования - путь, открытый человеку Христом и отсчитываемый от Его Голгофы. Это путь, который не кончается, с него нельзя свернуть 
и нельзя, ритуально завершив его, вернуться в человеческую повседневность, как после архаической инициации. Не случайно, что параллельно истории Ники Дудорова, практически одновременно с ней, проходит один из этапов своей духовной мистерии Юра Живаго, о чем мы узнаем в предшествующей 6 главе романа. Подробный ее анализ не входит сейчас в наши задачи, наметим лишь смысловой центр тех сакрально-значимых событий, которые совершаются с Юрой. Он тоже символически спускается в нижний мир, но не для того, чтобы спасти и утвердить свое «я», а для того, чтобы отмолить у Господа душу умершей матери. Она, по его интуициям, должна пребывать в Раю, но Юре тяжела даже малейшая мысль о том, что это может быть иначе. Он стремится спасти ее душу даже от потенциальной самой малой возможности лишиться Царства Небесного. Для такой, как она праведницы, подобная возможность почти невероятна, но мир любви, в котором живет Юра, в отличие от мира ритуала, жаждет непрерывного творчества духа и ждет ежемгновенных душевных трудов. Поэтому Юра всеми силами своей недетски взрослой души молится за нее, и, ценой «безумного превышения сил», теряет сознание в результате экстатического самоотрешения. Об особой сакральной значимости любящежертвенной молитвы за ближнего говорит и тот факт, что духовно погибающий отец Юры, за душу которого у мальчика уже не достает сил помолиться, буквально в тот же самый момент погибает и физически; параллелизм этих ситуаций в романе совершенно очевиден и глубоко символичен.

Мистерия Живаго - это не просто инициация (возрастная, психологическая или социальная), это Посвящение ${ }^{1}$ в высшее духовное Откровение о бытии, и совершается оно не единовременно, а на протяжении всей его жизни, обращая ее в Путь служения, творчества, любви. События, изображенные в шестой главе один из ключевых этапов этого Пути, в котором трагические и мистериальные смыслы индивидуальной судьбы провиденциально «рифмуются» с судьбами страны, народа, эпохи.

\section{Литература}

Ибатуллина Г.М. Проблема жанровой полифонии в романе Б. Пастернака «Доктор Живаго» // Жанровое своеобразие русской литературы XVIII-XX веков. Самара, 2002. С. 177-188.

Ибатуллина Г.М. Человек в параллельных мирах: художественная рефлексия в поэтике чеховской прозы. Стерлитамак, 2006а.

Ибатуллина Г.М. Первое Посвящение Юрия Живаго // Кормановские чтения. Ижевск, 2006б. Вып. 6. С. 226-234.

Ибатуллина Г.М. Метаромантизм как эстетическая позиция в лирике Ф. Глинки (к проблеме художественной рефлексии) // Русистика 2008. Язык, коммуникация, литература, культура. Шумен, 2008. С. 273-287.

Лосев А.Ф. Миф - число - сущность / Сост. А.А. Тахо-Годи; общ. ред. Ф.Ф. Тахо-Годи и И.И. Маханькова. М., 1994.

Пастернак Б.Л. Собр. соч.: В 5 т. М., 1989-1991. Т. 3: Доктор Живаго: Роман / Редкол.: А. Вознесенский, Д. Лихачев, Д. Мамлеев и др.; подгот. текста и коммент. В. Борисова и Е. Пастернака. М., 1990.

Пропп В.Я. Исторические корни волшебной сказки. Л., 1986.

Топоров В.Н. Хаос // Мифы народов мира: Энциклопедия: В 2-х т. М., 1991. T. 2: К-Я.

Тюпа В.И. Фазы мирового археосюжета как историческое ядро словаря мотивов // Материалы к «Словарю сюжетов и мотивов русской литературы». Новосибирск, 1996. Вып. 1: От сюжета к мотиву.

Фатеева Н.А. Поэт и проза: Книга о Пастернаке. М., 2003.

\footnotetext{
${ }^{1}$ Подробнее о логике Посвящений в становлении личности юного Юры Живаго мы
} говорим в других наших работах: [Ибатуллина, 2002, с. 177-188; 2006б, с. 226-234]. 